\title{
Epicentral distribution in 2007
}

\section{CHEN Pei-shan (陈培善)}

Institute of Geophysics, China Earthquake Administration, Beijing 100081, China

\section{CLC number: P315.5 Document code: $\mathrm{R}$}

For showing the epicentral distribution in and near China as well as all over the world, two epicentral maps for the earthquakes occurred last year are published annually in the 6-th issue each year. Figures 1 and 2 represent the epicentral distributions in and near China and all over the world in 2007, respectively.

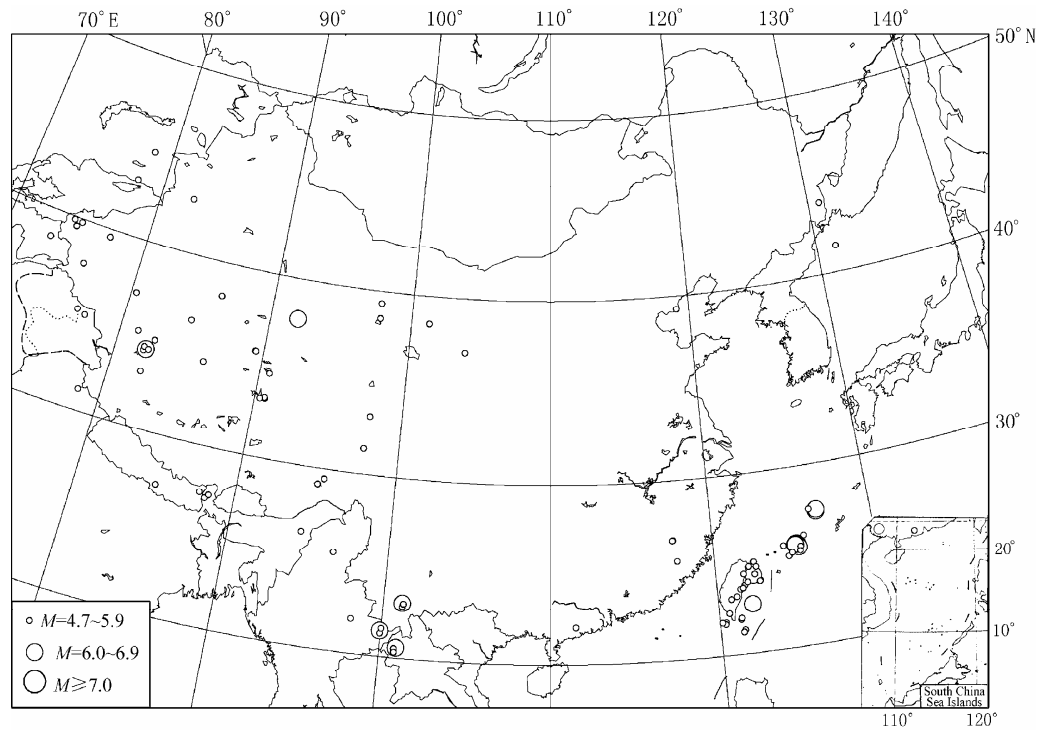

Figure 1 Epicentral distribution in and near China in 2007

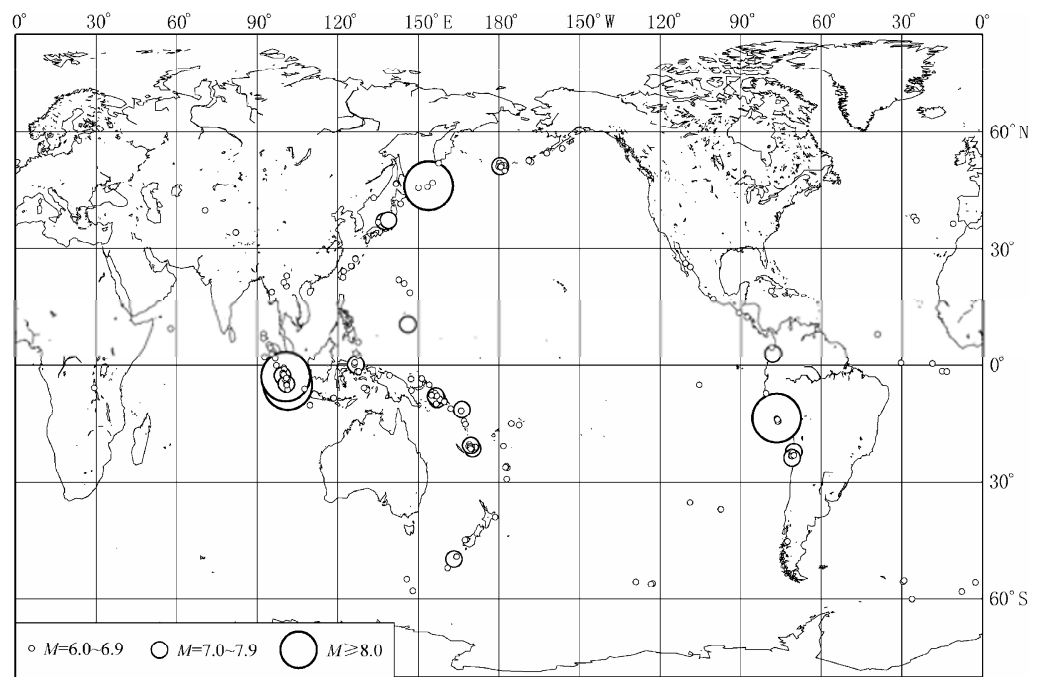

Figure 2 Epicentral distribution all over the world in 2007 